\title{
Preparation and characterization of the heat-resistant UV curable waterborne polyurethane coating modified by bisphenol A
}

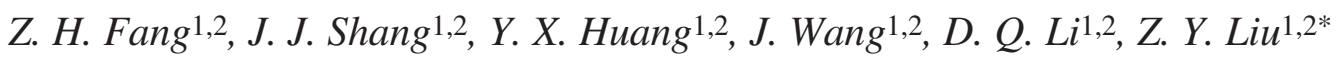 \\ ${ }^{1}$ College of Chemistry \& Chemical Engineering, Shihezi University, Shihezi, Xinjiang, 832003, People's Republic of \\ China \\ ${ }^{2}$ Xinjiang Bingtuan Key Laboratory for Green Processing of Chemical Engineering, Shihezi, Xinjiang, 832003, People's \\ Republic of China
}

\begin{abstract}
In this study, the modified ultraviolet (UV) curable waterborne polyurethane was obtained from isophorone diisocyanate (IPDI), polyethylene glycol (PEG, MW=600), $\alpha, \alpha$-dimethylol propionic acid (DMPA), hydroxyethyl acrylate (HEA) and bisphenol A. The rigid moiety was introduced into the main chain of polyurethane to improve its heat-resistance. The copolymer structure was confirmed by Fourier transform infrared spectroscopy (FT-IR). Thermal property and UV curable behavior of the coatings were investigated. The glass transition temperature $\left(T_{g}\right)$ of the modified film was determined by differential scanning calorimetry (DSC). Thermal gravimetric analysis (TGA) was employed to investigate the thermal stability of the modified film. The results show that the average particle diameters increased from 69.25 to $95.12 \mu \mathrm{m}$ as the content of bisphenol A increased from 0.00 to $9.25 \%$. The optimum bisphenol A dosage was $7.23 \%$ (wt $\%$ ), the $T_{g}$ of the modified film increased by $7.07^{\circ} \mathrm{C}$ and $5 \%$ weight-loss temperature $\left(233^{\circ} \mathrm{C}\right)$ increased by $14^{\circ} \mathrm{C}$. The optimum irradiation time was 10-20 minutes after the coatings being painted on an armor plate at room temperature and initiator dosage was $5 \%(\mathrm{wt} \%)$ of the latex.
\end{abstract}

Keywords: coatings, waterborne polyurethane, bisphenol A, modification, heat-resistant

\section{Introduction}

Recently, environmental legislation is increasingly strict with coatings industry. The coatings technology is changed from traditional solvent-borne coatings to environmental friendly coatings [1]. Waterborne coatings are new safe materials that can reduce environmental pollution [2]. Because of the virtues in environmental protection, waterborne coatings which were rapidly developed in the past few years have been paid more and more attention and expected to substitute the solvent coatings. But the waterborne coatings are inferior to the solvent coatings for their low chemical resistance, scratch resistance and slow solidification [3]. Although ultraviolet (UV) radiation is a well-accepted technology for the fast curing of polymeric materials, the UV curable coatings have odor, emission monomers and are not zero-VOC emission [4]. Therefore, in order to overcome above disadvantages, UV curable waterborne coating is generated. Presently, because of many merits, including nonflammable, non-toxic, friendly environment, fast solidification, resistance to organic solvents and excellent mechanical properties [5-8], UV curable waterborne polyurethane coatings (UVWPU) have received more and more attention in the past few 
years and their development has resulted in a wide variety of technical approaches in industrial applications, such as fast drying protective coatings, printing inks and adhesives $[9,10]$. But they have some inferior properties such as low heat resistance and weak tensile strength when the external temperature exceeds $80^{\circ} \mathrm{C}$ [11]. Thus, the heat resistance of the UVWPU was improved by several scholars. The conventional method of preparing the heat resistance UV curable waterborne coatings is by way of synthesizing hyperbranched polymer introducing the vinyl groups into the polyurethane chains. For example, Xiong et al. [12] synthesized dendritic poly(urethane acrylate) by using 2,4-toluidene diisocyanate, $\beta$-hydroxyethyl arcylate, glycidyl methacrylate and polyol under the condition of the thermal degradation temperature of $208^{\circ} \mathrm{C}$. It is well known that the thermal degradation of polyurethane contains two steps and the first one is related to the hard segments [13]. However, the heat resistance of the film was improved by synthesizing special hard segment [14].

Therefore, in this article, a series of novel modified polymers of UVWPU are prepared in three steps. Firstly, the preparation of UVWPU prepolymer is synthesized from isophorone diisocyanate (IPDI), polyethylene glycol (PEG, MW=600), 2,2-dimethylol propionic acid (DMPA). Secondly, the UVWPU chain is extended by bisphenol A. finally, the polyurethane main chain is end capped with hydroxyethyl acrylate (HEA), neutralized with triethylamine (TEA) and dispersed with deionized water. The rigid moiety is introduced into the polyurethane molecule by using bisphenol A to improve the thermal properties of coating.

At present, the particle size of the modified UVWPU dispersions was investigated by Microtrac S3500 (Microtrac Montgomeryville, PA, USA). The structure and properties of the modified film were studied by several techniques such as FTIR (Fourier transform infrared spectroscopy), DSC (differential scanning calorimetry) and TGA. The results show that the modified film has a good heatresistance.

\section{Materials and methods}

\subsection{Materials}

IPDI (pure grade, 98\%) was purchased from Alfa Aesar (Massachusetts, USA) and used without fur- ther purification. Dibutyltin dilaurate (pure grade 90\%) was supplied by Energy Chemical (Shanghai, China) as a catalyst. PEG600 (AR) was produced by Shanghai Sangon Biological Engineering Technology and Services Co., Ltd. (Shanghai, China) which was dried for $5 \mathrm{~h}$ at $105^{\circ} \mathrm{C}$ in the vacuum oven before use. DMPA (pure grade 99\%) was obtained from Alfa Aesar (Massachusetts, USA), which was purified and dried at $105^{\circ} \mathrm{C}$ for $4 \mathrm{~h}$ in the vacuum oven. Triethylamine (TEA) and acetone (AR) were obtained from Fuyu (Tianjing) Industry of Fine Chemicals Co., Ltd. (Tianjing, China), which were dried for one week with $4 \AA$ molecular sieves (AR, Shanghai Zeolite Molecular Sieve Co., Ltd, China) before use. 2-hydroxyl-2-methylpropiophenone (pure grade, 97\%) was supplied by Sigma Aldrich Inc. (Shanghai, China). HEA (pure grade 97\%) was supplied by Energy Chemical (Shanghai, China). Bisphenol A (pure grade 99\%) was supplied by Bio Basic Inc. (Toronto, Canada). HEA and bisphenol A were used without further purification.

\subsection{Preparation of aqueous dispersion}

The preparing process of dispersion is shown in Figure 1. The synthesis was carried out in a fournecked, round-bottomed flask equipped with mechanical stirrer, dropping funnel, nitrogen protector and reflux condenser with a drying tube. The reaction temperature was controlled by using a constant-temperature oil bath. Firstly, IPDI, PEG600, and DMPA were added with suitable mole ratio. Then, dibutyltin dilaurate was added into the flask under moderate stirring. The reaction was conducted at $85^{\circ} \mathrm{C}$ until the theoretical $-\mathrm{NCO}$ group content reached. Then, the bisphenol A was added into the system and reacted at $75^{\circ} \mathrm{C}$ for $2 \mathrm{~h}$. Thereafter the HEA and catalyst were added into the system and reacted at $75^{\circ} \mathrm{C}$. The end point of reaction was determined by the disappearance of $-\mathrm{NCO}$ stretching peak through infrared (IR) spectroscopy. The acetone was added into the flask to adjust the viscosity of the solution in course of reaction. When the reaction was completed, the reaction system was cooled down to $25^{\circ} \mathrm{C}$ and the neutralizing agent (TEA) was added and stirred for 30 minutes. The aqueous dispersion was obtained by adding deionized water as the dispersion medium to the reaction system under vigorous stirring. The UV 


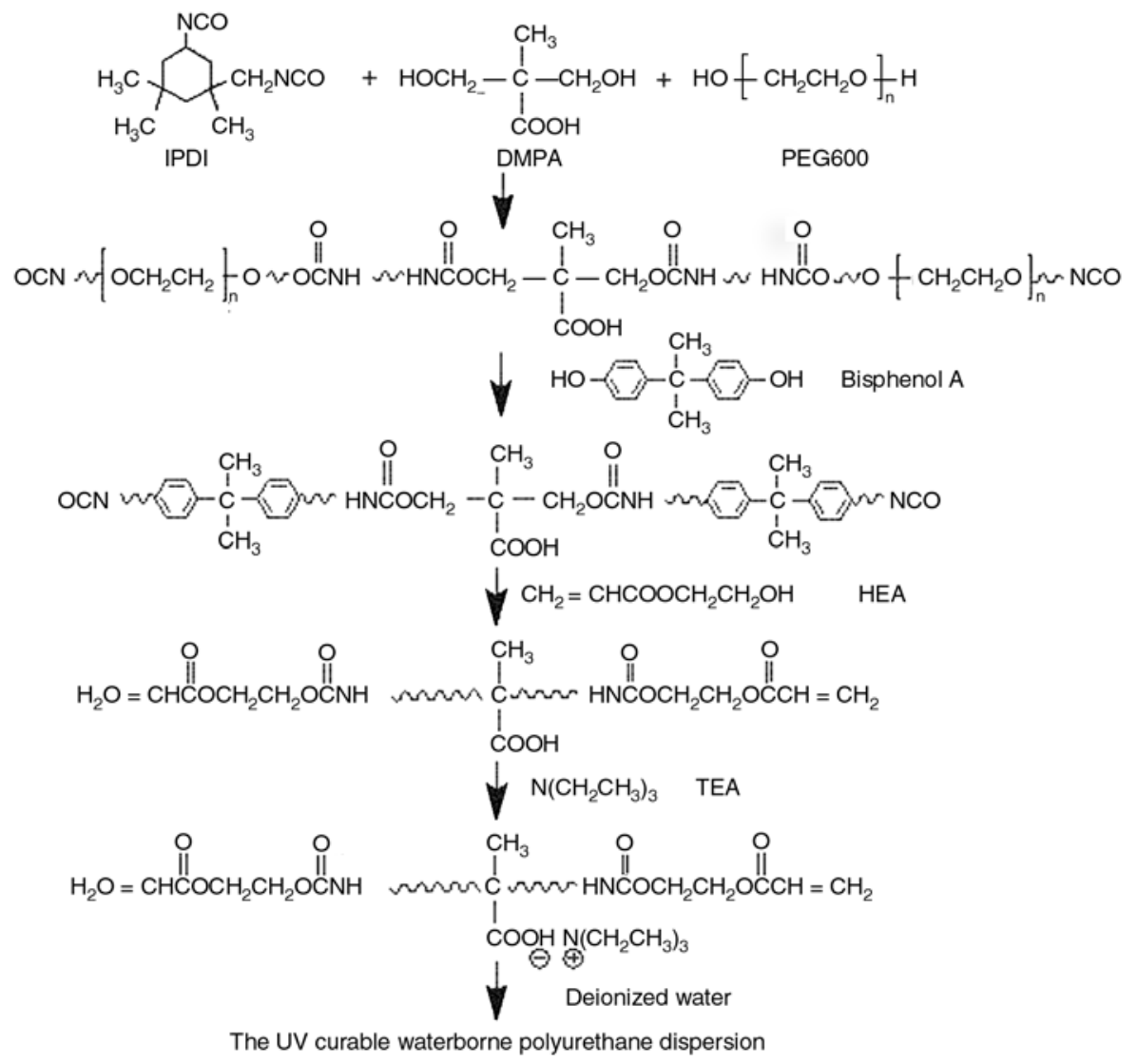

Figure 1. The preparation process of the UVWPU dispersion

curable waterborne polyurethane dispersion (solid content $25 \%$ ) was obtained after removal of the acetone from the reaction system by rotary vacuum evaporation.

The varying content of $-\mathrm{NCO}$ during the reaction was determined by the di- $n$-butylamine back titration method. The theoretical value of $-\mathrm{NCO}$ was calculated by Equation (1) [5]:

$\mathrm{NCO}[\%]=\frac{\left(M_{\mathrm{NCO}}-M_{\mathrm{OH}}\right) \cdot 42}{W_{\mathrm{NCO}}+W_{\mathrm{OH}}} \cdot 100$

where $M_{\mathrm{NCO}}$ was the mole number of $\mathrm{NCO}$ group in the system. $M_{\mathrm{OH}}$ was the mole number of $\mathrm{OH}$ group. $W_{\mathrm{NCO}}$ was the weight of diisocyanate. $W_{\mathrm{OH}}$ was the weight of alcohols.

\subsection{Preparation of UV cured films}

The UVWPU films were formed by irradiating with UV mercury lamp $(15 \mathrm{~W})$ in the period of time with suitable photoinitiator 2-hydroxyl-2-methylpropiophenone based on the resins onto an armor plate at room temperature and followed by drying the film $48 \mathrm{~h}$ at room temperature after water was evaporated until reaching a constant weight before test.

\subsection{Characterization and measurements}

\subsubsection{IR analysis}

The infrared (IR) spectra were recorded with a Fourier transform infrared spectroscopy (FT-IR) instrument in the $400-4000 \mathrm{~cm}^{-1}$ region. Samples were coated directly on to the surface of a $\mathrm{KBr}$ crystal, respectively, and measured after film forming and drying.

\subsubsection{Particle sizes and distributions}

The particle size distributions of the dispersion were measured by using the Microtrac S3500 (Microtrac Inc., Montgomeryville, PA, USA) laser light particle size analysis apparatus. Samples were diluted with water into an appropriate concentration as indicated by the instrument. Test temperature: $25^{\circ} \mathrm{C}$

\subsubsection{TGA analysis}

The TGA of the UVWPU films were carried out on a Model ZRY-2P (Shanghai Precision and Scientific Instrument Co., Ltd., China) thermal analyzer and the samples were placed in a platinum sample 
pan and characterized by performing a scan from 50 to $700^{\circ} \mathrm{C}$ at heating rate of $10^{\circ} \mathrm{C} / \mathrm{min}$ in $\mathrm{N}_{2}$ atmosphere.

\subsubsection{DSC analysis}

The $T_{g}$ of UV cured films is evaluated by Mettler DSC1 (Mettler Toledo, Switzerland) thermal analyzer at temperatures from -100 to $250^{\circ} \mathrm{C}$ and $10^{\circ} \mathrm{C} /$ min heating rate in $\mathrm{N}_{2}$ atmosphere.

\subsubsection{Gel contents of the film}

The ultraviolet curable behaviors of UVWPU were detected in gel content. The gel ratio $(G)$ of the UVWPU specimen was tested by immersing the UVWPU films in acetone at $48 \mathrm{~h}$ and was calculated by Equation (2) $[15,16]$ :

$G=\frac{M_{1}}{M_{2}} \cdot 100$

where $M_{2}$ and $M_{1}$ are the weight of UVWPU film before and after purification, respectively.

\section{Results and Discussion}

\subsection{IR Analysis}

The structure of the UVWPU was confirmed by FT-IR as shown in Figure 2. The typical absorption peaks of polyurethane could be seen from the figure at $3310-3360 \mathrm{~cm}^{-1}$ (NH stretching vibration), $2850-2950 \mathrm{~cm}^{-1} \quad\left(-\mathrm{CH}_{2}\right.$ stretching vibration), $1714 \mathrm{~cm}^{-1}$ (C=O stretching vibration), $1615 \mathrm{~cm}^{-1}$ ( $-\mathrm{C}_{6} \mathrm{H}_{5}$ stretching vibration), $1540 \mathrm{~cm}^{-1}$ (NH deformation vibration), $1461 \mathrm{~cm}^{-1}$ (- $\mathrm{CH}_{2}$ deformation vibration) and $1124 \mathrm{~cm}^{-1}(\mathrm{C}-\mathrm{O}-\mathrm{C}$ stretching vibration), respectively. The $-\mathrm{NCO}$ absorption appeared at $2265 \mathrm{~cm}^{-1}$ for prepolymer and disappeared for the product which indicated that $-\mathrm{NCO}$ groups had been blocked for the product. The $-\mathrm{C}_{6} \mathrm{H}_{5}$ absorption appeared at $1615 \mathrm{~cm}^{-1}$ for polymer after chain extension which indicated that bisphenol A had been introduced into the main chain of the polyurethane. The spectrum of the product obviously showed the absorption peaks at $1631 \mathrm{~cm}^{-1}$ $(\mathrm{C}=\mathrm{C}$ stretching vibration), which demonstrated that the $\mathrm{C}=\mathrm{C}$ bond had been incorporated in the polyurethane chains. In addition, the spectra of UVWPU film displayed that the $\mathrm{C}=\mathrm{C}$ bond decreased significantly after UV radiation, which

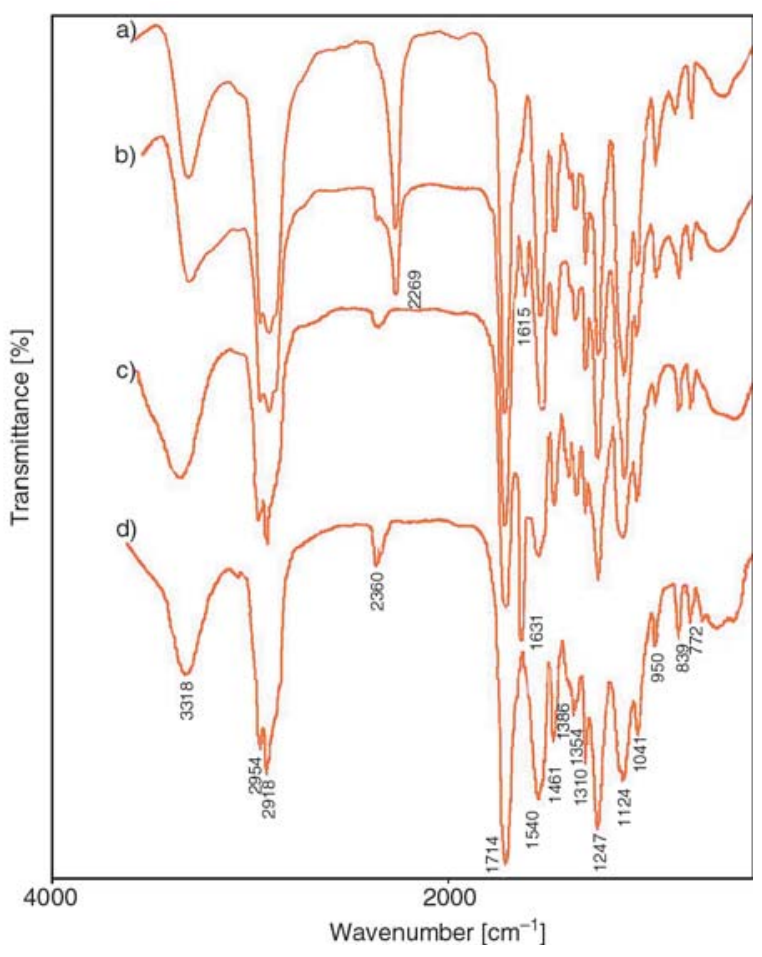

Figure 2. The FT-IR spectra of the modified UVWPU:

a) prepolymer, b) polymer after chain extension,

c) end-capping polymer, d) cured film)

illustrated that the $\mathrm{C}=\mathrm{C}$ bond of the polyurethane chains has been polymerized.

\subsection{Average particle size of the UVWPU dispersions}

It is well known that the average particle size and dispersibility of the UVWPU are governed by several factors such as the hydrophilicity, prepolymer viscosity, ionic group position, chain rigidity, etc. $[17,18]$. In this study, the molar ratio of $-\mathrm{NCO} /$ $-\mathrm{OH}$, the mass ration of DMPA, HEA and PEG are fixed to a number separately. We have synthesized a series of UVWPU with different content of the bisphenol A. The average particle diameters of the UVWPU dispersions are shown in Figure 3. The average particle diameters of the suspension are mainly affected by the mass ration of bisphenol A and DMPA. Figure 3 and Table 1 show the content of DMPA in the main chain decrease and the dilution stability of the suspension becomes worse as the content of bisphenol A increased from 0.00 to $9.25 \%$, and the average particle diameters increased from 69.25 to $95.12 \mu \mathrm{m}$ obviously, the reason of which was the decreasing of the hydrophilicity content of the chains and the increased chain rigidity after using bisphenol $\mathrm{A}$ as the chain extender. 
Table 1. Suspension stability of the UVWPUs at different content of DMPA

\begin{tabular}{|c|c|c|c|c|}
\hline \multirow{2}{*}{$\begin{array}{c}\text { Bisphenol A } \\
\text { content [wt } \%]\end{array}$} & \multirow{2}{*}{$\begin{array}{c}\text { DMPA } \\
\text { content }[\mathbf{w t} \%]\end{array}$} & Before & After & \multirow{2}{*}{ Dilute stability $^{\mathbf{b}}$} \\
\cline { 3 - 4 } & 9.93 & Translucence & Translucence & Translucence \\
\hline 0.00 & 9.42 & Translucence & Translucence & Translucence \\
\hline 2.67 & 8.92 & Translucence & Translucence & Translucence \\
\hline 5.06 & 8.50 & Translucence & Translucence & Flocculation \\
\hline 7.23 & 8.10 & Translucence & Translucence & Delamination, flocculation \\
\hline 9.25 & \multicolumn{2}{|c}{} \\
\hline
\end{tabular}

aRev: $3000 \mathrm{r} / \mathrm{min}$, time: $15 \mathrm{~min}$

bLatex was diluted with adding deionized water (solid content of the diluted latex, 3\%)

and deposited $48 \mathrm{~h}$ before observing experimentally

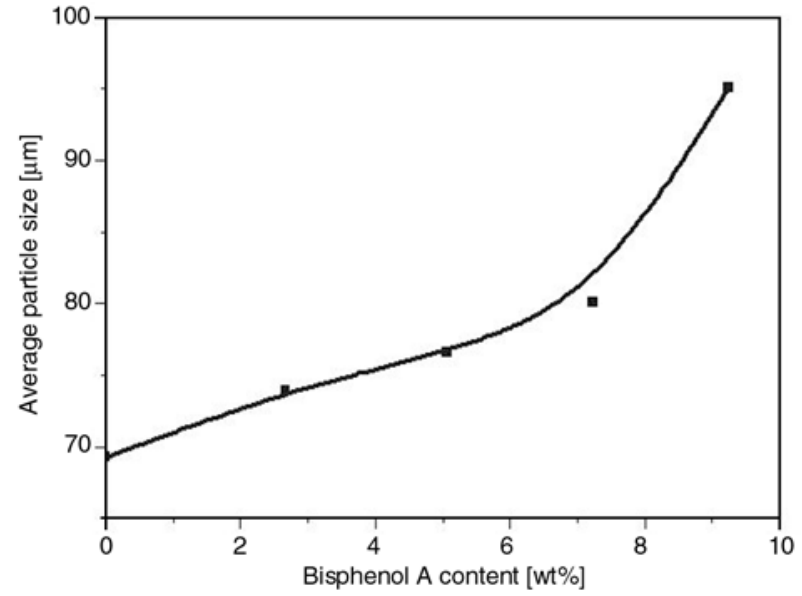

Figure 3. Effect of the bisphenol A content [wt\%] on the latex average particle size

The experiment result of the suspension stability is shown in Table 1.

\subsection{Thermal properties}

In this study, heat-resistance of the UVWPU film with different content of the bisphenol A is measured according to GB 1735-79 (Table 2). The date of the Table 2 displayed that the heat-resistance of the UVWPU film without bisphenol A is bad, but the heat-resistance of the UVWPU film is increased with the addition of the bisphenol A as chain extender gradually increasing from 0.00 to $7.23 \%$. In our study, we found that the UVWPU film is the best heat-resistance during the content of the bisphenol A at $7.23 \%$. The explanation of this fact is that the chain rigidity is increased and the cross-linking density is decreased which is due to the fact that the content of HEA of system decreases as the content of bisphenol A increased from 0.00 to $9.25 \%$. When the content of bisphenol A exceeds $7.23 \%$, the heat-resistance is decreased by the reduction of the cross-link density.

The TGA curves of the unmodified film and the modified film (content of bisphenol A at $7.23 \%$ ) are shown in Figure 4. The results showed that the sample UVWPU without bisphenol A had lower initial thermal decomposition temperature than that with bisphenol A as the chain extender. The results of TGA for the modified film obviously indicated the $5 \%$ weight-loss temperature of the modified film at $233^{\circ} \mathrm{C}$, which was improved by $14^{\circ} \mathrm{C}$ than

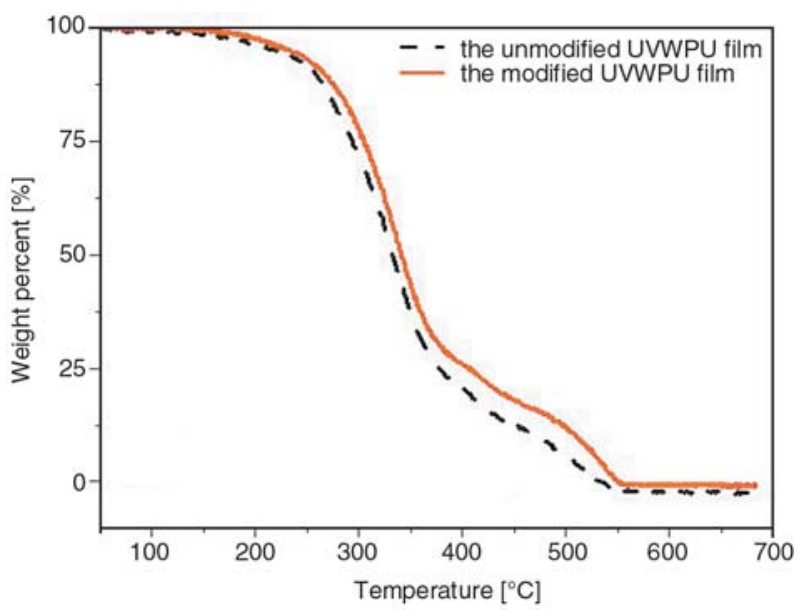

Figure 4. The TGA curves of the UVWPU films at the heating rate of $10^{\circ} \mathrm{C} / \mathrm{min}$

Table 2. Thermal properties of UVWPU films at different content of bisphenol A

\begin{tabular}{|c|c|c|c|c|c|}
\hline \multirow{2}{*}{$\begin{array}{c}\text { Bipsphenol A } \\
\text { content [wt } \%\end{array}$} & \multicolumn{5}{|c|}{ Thermal properties of UVWPU films } \\
\cline { 2 - 5 }
\end{tabular}

aTest time is $2 \mathrm{~h}$, acceptance means the film without color change, crinkle, desquamate, dehisce and frothy 
the UVWPU without using bisphenol A. In several studies, it has been concluded that the first and second stages of degradation of polyurethane copolymers are related to the degradations of the hard and soft segments, respectively [11]. The UVWPU polymer coating film in the TGA test presents two stages of degradation associated with the degradations of urethane hard segments and PEG600 soft segment. The unmodified film exhibits lower temperature of $5 \%$ weight loss due to the high aliphatic chain of hard segments. Notably, the urethane groups of the modified film after benzene ring incorporating in hard segment decompose at higher temperature than the urethane groups of the unmodified film, implying that the degradation of urethane groups of the modified film is hindered by the aromatic chains.

The DSC curves of the unmodified UVWPU film and the modified UVWPU film (content of bisphenol $\mathrm{A}$ at $7.23 \%$ ) are shown in Figure 5.

Figure 5 showed that the unmodified UVWPU film was observed only one $T_{g}$ at $34.86^{\circ} \mathrm{C}$, which is lower than that of the modified UVWPU film (dosage of bisphenol A at 7.23\%) and the $T_{g}$ of the modified film increased by $7.07^{\circ} \mathrm{C}$ (about $41.93^{\circ} \mathrm{C}$ ). The explanation is that the chain rigidity is introduced by using bisphenol $\mathrm{A}$ as the chain extender, the chain movement is confined, which increases the $T_{g}$ value. But we can observe a weak peak $\left(139.50^{\circ} \mathrm{C}\right)$ in the DSC curve of the modified film, which might be due to the evaporation of water. The UVWPU film with only one $T_{g}$ might be due to the chain high cross-linking density which was formed by irradiating with UV mercury lamp. In addition, the soft-segment and hard-segment have nicer compatibility.

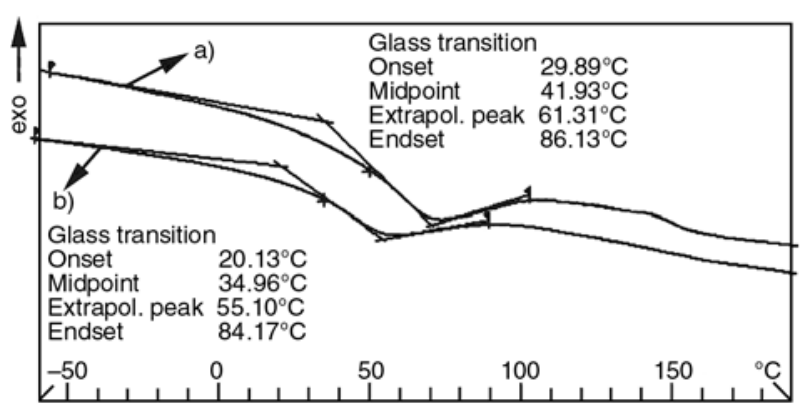

Figure 5. The DSC curve of the films at the heating rate of $10^{\circ} \mathrm{C} / \mathrm{min}$ : a) the modified UVWPU film, b) the unmodified UVWPU film

\subsection{Ultraviolet curable behaviors}

The most important parameter for the UV curing process is the gel rate. In this study, the contents of initiator (4\%) and the content of bisphenol A (7.23\%) are fixed separately. We have investigated the effect of different drying times before irradiation on the UV curing process (Figure 6). Figure 6 shows that the sample with drying time at $20 \mathrm{~min}$ exhibits the highest gel rate and the curing rate of the modified UVWPU film increases with the increasing of irradiation time at the beginning of irradiation before reaching a constant value. It can also be seen from Figure 6 that the curing rate presents the different variation tendency and increases rapidly. Comparing the sample curve with drying time at $10 \mathrm{~min}$ to that at $20 \mathrm{~min}$, we find that the curing rate of the former approaches to that of latter and the curing process is absolutely accomplished after $30 \mathrm{~min}$. Reason for this is the higher water content at the beginning of the irradiation and the low concentration of active center and the curing rate. Therefore, the optimum irradiation time is the 10-20 min after the resins onto an armor plate at room temperature.

There is the optimum initiator content in the specifically system. In this study, the content of bisphenol A $(7.23 \%)$ is a fixed number. We have investigated the effect of initiator content on the UV curing process (Figure 7). Comparing the sample with initiator contents at 4 and 6\%, Figure 7 shows that the highest gel ratio of sample happens at an initiator content of $5 \%$, which is caused by the lower energy utilization rate and active center con-

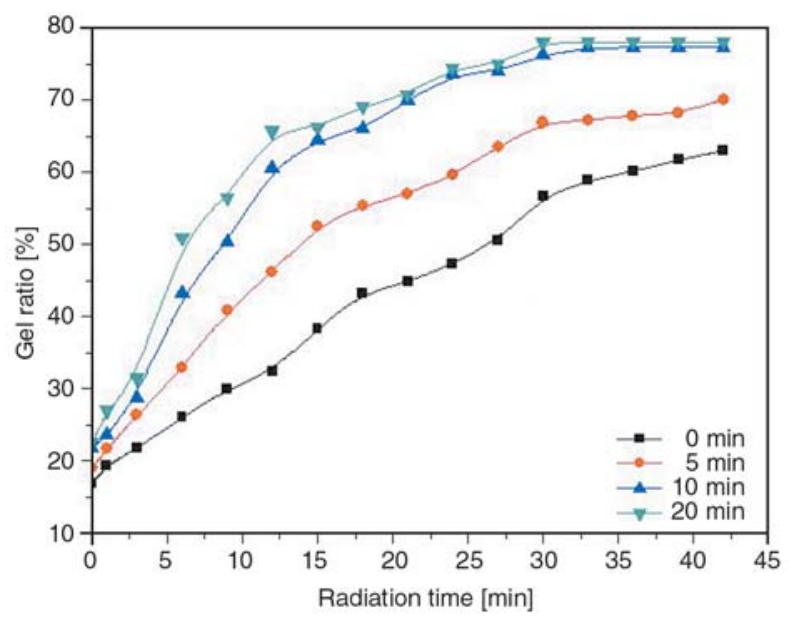

Figure 6. Relationship between the gel ratio for different drying time and the radiation time 


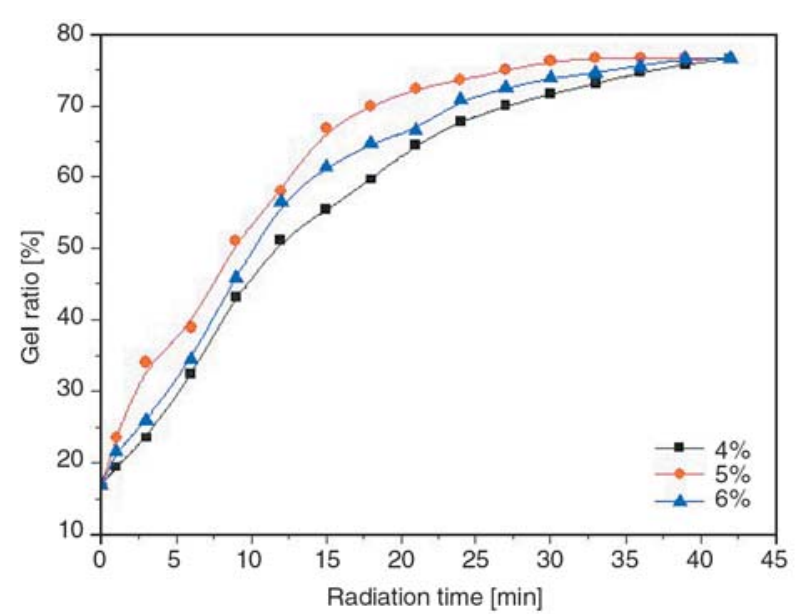

Figure 7. Relationship between the gel ratio for different initiator content and the photo-irradiation time

centration when the initiator content was low. On the other hand, the active center concentration increases with the increasing of the initiator content, which results in the chain termination in superfluous active center coupling each other [19]. Therefore, it can be revealed that the optimum initiator content is $5 \%$.

\section{Conclusions}

We have successfully synthesized the novel ultraviolet curable waterborne polyurethane coating by introducing the rigid moiety into the main chain of the polyurethane using bisphenol A as chain extender. The results showed that the optimum bisphenol A dosage was $7.23 \%$ (wt $\%$ ), the average particle diameters increased from 69.25 to $95.12 \mu \mathrm{m}$ as the content of bisphenol A increased from 0.00 to $9.25 \%$. Comparing with the unmodified UVWPU, the obvious advantage of heat resistance of modified UVWPU film was displayed after the rigid chain was introduced into the polyurethane main chain. Otherwise, the $T_{g}$ of the modified UVWPU was $41.93^{\circ} \mathrm{C}$ which increased by $7.07^{\circ} \mathrm{C}$ and the $5 \%$ weight-loss temperature $\left(233^{\circ} \mathrm{C}\right)$ of the modified UVWPU film increased by $14^{\circ} \mathrm{C}$. The curing process indicated that the optimum irradiation time was 10-20 min after the resins onto an armor plate at room temperature and initiator content was $5 \%$.

\section{Acknowledgements}

Financial support from the Shihezi University science fund (NO. RCZX200712) is acknowledged.

\section{References}

[1] Hwang H-D., Moon J-I., Choi J-H., Kim H-J., Kim S. D., Park J. C.: Effect of water drying conditions on the surface property and morphology of waterborne UVcurable coatings for engineered flooring. Journal of Industrial and Engineering Chemistry, 15, 381-387 (2009).

DOI: $10.1016 /$ j.jiec.2008.11.002

[2] Athawale V. D., Kulkarni M. A.: Synthesis, characterization, and comparison of polyurethane dispersions based on highly versatile anionomer, ATBS, and conventional DMPA. Journal of Coatings Technology and Research, 7, 189-199 (2010). DOI: $\underline{10.1007 / \mathrm{s} 11998-009-9184-2}$

[3] Rahman M. M., Lee W-K.: Properties of isocyanatereactive waterborne polyurethane adhesives: Effect of cure reaction with various polyol and chain extender content. Journal of Applied Polymer Science, 114, 3767-3773 (2009).

DOI: $10.1002 / a p p .30848$

[4] Lee M. H., Choi H. Y., Jeong K. Y., Lee J. W., Hwang T. W., Kim B. K.: High performance UV cured polyurethane dispersion. Polymer Degradation and Stability, 92, 1677-1681 (2007).

DOI: $10.1016 /$ j.polymdegradstab.2007.06.006

[5] Bai C. Y., Zhang X. Y., Dai J. B., Li W. H.: A new UV curable waterborne polyurethane: Effect of $\mathrm{C}=\mathrm{C}$ content on the film properties. Progress in Organic Coatings, 55, 291-295 (2006).

DOI: 10.1016/j.porgcoat.2005.12.002

[6] Bai C. Y., Zhang X. Y., Dai J. B.: Effect of the hard segment on the properties of UV curable waterborne blocked polyurethanes. Journal of Polymer Research, 15, 67-73 (2008). DOI: $10.1007 / \mathrm{s} 10965-007-9144-4$

[7] Asif A., Shi W. F., Shen X. F., Nie K. M.: Physical and thermal properties of UV curable waterborne polyurethane dispersions incorporating hyperbranched aliphatic polyester of varying generation number. Polymer, 46, 11066-11078 (2005).

DOI: $10.1016 /$ j.polymer.2005.09.046

[8] Yang Z. L., Wicks D. A., Hoyle C. E., Pu H. T., Yuan J. J., Wan D. C., Liu Y. S.: Newly UV-curable polyurethane coatings prepared by multifunctional thiol- and ene-terminated polyurethane aqueous dispersions mixtures: Preparation and characterization. Polymer, 50, 1717-1722 (2009).

DOI: $10.1016 /$ j.polymer.2008.12.018

[9] Asif A., Hu L. H., Shi W. F.: Synthesis, rheological, and thermal properties of waterborne hyperbranched polyurethane acrylate dispersions for UV curable coatings. Colloid and Polymer Science, 287, 10411049 (2009).

DOI: $10.1007 / \mathrm{s} 00396-009-2062-8$ 
[10] Sow C., Riedl B., Blanchet P.: Kinetic studies of UVwaterborne nanocomposite formulations with nanoalumina and nanosilica. Progress in Organic Coatings, 67, 188-194 (2010).

DOI: $10.1016 /$ j.porgcoat.2009.10.002

[11] Chuang F-S., Tsi H-Y., Chow J-D., Tsen W-C., Shu Y-C., Jang S-C.: Thermal degradation of poly(siloxane-urethane) copolymers. Polymer Degradation and Stability, 93, 1753-1761 (2008).

DOI: 10.1016/j.polymdegradstab.2008.07.029

[12] Xiong Y-Q., Lu W-H., Xia X-N., Zhang X-H., Xu W-J.: Synthesis of PUA dendrimer and its UV-curing properties (in Chinese). Journal of Hunan University (Natural Sciences), 33, 81-84 (2006).

[13] Santos C. C., Delpech M. C., Coutinho F. M. B.: Thermal and mechanical profile of cast films from waterborne polyurethanes based on polyether block copolymers. Journal of Materials Science, 44, 1317-1323 (2009).

DOI: $10.1007 / \mathrm{s} 10853-009-3272-7$

[14] Yang D. Y., Zhang P., Qiu F. X., Cao, G. R.: Preparation and properties of the internal crosslinking waterborne polyurethaneurea (in Chinese). Chemical Industry and Engineering Progress, 27, 270-273 (2008).
[15] Shao C-H., Wang T-Z., Chen G-N., Chen K-J., Yeh JT., Chen K-N.: Aqueous-based polyurethane with dual-functional curing agent. Journal of Polymer Research, 7, 41-49 (2000). DOI: $10.1007 / \mathrm{s} 10965-006-0102-3$

[16] Kong X., Li S. M., Qu J. Q., Chen H. Q.: Self-emulsifying hydroxy acrylic polymer dispersions for two component waterborne polyurethane coatings. Journal of Macromolecular Science Part A: Pure and Applied Chemistry, 47, 368-374 (2010).

DOI: $\underline{10.1080 / 10601320903539330}$

[17] Bao L-H., Lan Y-J., Zhang S-F.: Synthesis and properties of waterborne polyurethane dispersions with ions in the soft segments. Journal of Polymer Research, 13, 507-514 (2006). DOI: $10.1007 / \mathrm{s} 10965-006-9073-7$

[18] Park S. H., Chung I. D., Hartwig A., Kim B. K.: Hydrolytic stability and physical properties of waterborne polyurethane based on hydrolytically stable polyol. Colloids and Surfaces A: Physicochemical and Engineering Aspects, 305, 126-131 (2007). DOI: 10.1016/j.colsurfa.2007.04.051

[19] Han S-D., Jin Y-Z., Wang F.: Effects on the curing rate of ultraviolet-curable waterborne system (in Chinese). Journal of Beijing University of Chemical of Chemical Technology, 29, 30-32 (2002). 